\title{
Mentor Us: A Formal Mentoring Program for Nurses in Graduate Education
}

Jennifer Bell

University of Alberta, jbell2@ualberta.ca

Nichole Marks

University of Alberta, nmarks@ualberta.ca

Jennifer Hermann

University of Alberta, jhermann@ualberta.ca

Amanda Klooster

University of Alberta, klooster@ualberta.ca

Follow this and additional works at: https://qane-afi.casn.ca/journal

Part of the Nursing Commons

\section{Recommended Citation}

Bell, Jennifer; Marks, Nichole; Hermann, Jennifer; and Klooster, Amanda (2017) "Mentor Us: A Formal Mentoring Program for Nurses in Graduate Education," Quality Advancement in Nursing Education - Avancées en formation infirmière: Vol. 3: Iss. 2, Article 6.

DOI: https://doi.org/10.17483/2368-6669.1098

This Article is brought to you for free and open access by Quality Advancement in Nursing Education - Avancées en formation infirmière. It has been accepted for inclusion in Quality Advancement in Nursing Education - Avancées en formation infirmière by an authorized editor of Quality Advancement in Nursing Education - Avancées en formation infirmière. 


\section{Mentor Us: A Formal Mentoring Program for Nurses in Graduate Education}

\section{Cover Page Footnote}

We would like to gratefully acknowledge the support and encouragement from Dr Olive Yonge. Nous aimerions sincèrement remercier Dre Olive Yonge pour son soutien et son encouragement. 
Typically, employees with graduate degrees bring unique competencies to their professions such as advanced communication skills, experience with complex problem solving, project management experience, and the ability to contribute to a complex understanding of their respective fields of work (Edge \& Munro, 2015). As such, it is important that universities can recruit and retain graduate students because they are often seen as leaders within their professions. Unfortunately, there are multiple barriers to the completion of graduate studies including the highly stressful, isolating, and competitive nature of graduate education. To temper these barriers, attention to relational aspects of knowing and relating to colleagues can improve satisfaction and productivity of individuals in an array of organisations and institutions (Snowden \& Hardy, 2012). To mitigate these concerns and to improve the graduate school experience, graduate students in the Faculty of Nursing at a large research university in western Canada, united to create a student-conceived and operated mentorship program called Mentor Us.

In early 2013, four Master of Nursing (MN) students began to conceptualize Mentor Us for graduate students with the intent of improving student collegiality, building connections within the faculty and community, and providing opportunities for peers to connect. They envisioned a voluntary mentorship program that offered the opportunity for peer-to-peer mentorship in dyads consisting of one mentor and one mentee. Together, they mapped out a development plan with priorities such as establishing the program's mission, vision, and purpose (Appendix), designing the program, securing faculty stakeholder support and funding, and determining recruitment and promotion strategies to encourage uptake by program users.

There are three aims of this paper: first, to outline the current state of nursing graduate education in Canada; second, to present the process of building and maintaining a formal mentorship program for nurses in graduate studies; and third, to describe the vision of the program moving forward, to outline lessons learned during the development and operation of the program, and to review strategies to ensure future program success. This paper contributes to the nursing body of knowledge by offering a unique way to mitigate the concerns of nursing graduate students by fostering peer mentorship relationships and enhancing community connections. It provides a concrete example of the development of such a program and presents an honest critique about how to improve the program for future students.

\section{Background}

The goals of the literature review are threefold. First, we review research supporting the expectations and importance of graduate degree-prepared nurses to the discipline of nursing. Second, we outline the current state of graduate studies in Canada, discuss concerns about attrition rates in this group and review research related to graduate school experiences specific to nursing. Third, we discuss literature related to mentorship in graduate programs in nursing.

Graduate degree-prepared nurses are expected to have leadership skills, incorporate knowledge from other disciplines, promote evidence-based research knowledge utilization in practice, use theoretical principles to support fundamentals of nursing practice, and critically analyze policy to directly impact health systems in Canada (Canadian Nurses Association, 2008). These indeed are broad claims and are supported by international literature. Research has demonstrated that graduate degree-prepared nurses have increased confidence and self-esteem, have enhanced communication skills, incorporate and apply research into practice, and are more analytical in their decision-making (Cotterill-Walker, 2012). Research by Drennan (2010) found 
that master's degree graduates in nursing have "growth in critical thinking ability" (p. 429) after program completion. Another study suggested that nurses who are master's level prepared demonstrated higher outcome competencies related to leadership and management (Drennan, 2012). Research has also shown that master's degree-prepared nurses impact the discipline of nursing by demonstrating enhanced professionalism, have increased personal and professional confidence, tend to have higher cognitive functioning, and use evidence-based practice more readily (Watkins, 2011). Specific to the Canadian context, there is a paucity of literature to support these assertions; however, there is research to endorse the integration of mentorship programs for new faculty members as a recruitment and retention strategy and to foster successful transition into new faculty positions (Sculley, 2015; Singh, Pilkington, \& Patrick, 2014).

Because a goal of nursing graduate education is to develop and foster leadership skills, it follows that these same nurses are increasingly being expected to undertake leadership roles within and outside of the traditional health care system. Advanced nursing education is needed which promotes the development of individuals with expertise in high-level thinking and management strategies who can respond to the complexities of a rapidly changing health care system (Pilon et al., 2014; Warren \& Mills, 2009). Leadership in nursing can "no longer be left as a future career development goal" (Symonds-Brown \& Milner, 2015, p. 11) but rather requires continuous development from undergraduate education to graduate studies to the end of one's career. If nurses are expected to undertake these pivotal positions, then graduate nursing education must be prepared to deliver excellent graduate programs and support students throughout the process.

In Canada, enrollment in full-time graduate studies is increasing. Over the last 30 years, entrance into doctoral programs has quadrupled (Tamburri, 2013). In the previous 20 years, fulltime entry into $\mathrm{PhD}$ programs has increased by $129 \%$ in Canada and by $157 \%$ in Alberta (Looker, 2015). During this same time, enrollments in master's degree programs have increased by $109 \%$ in Canada and by $139 \%$ in Alberta (Looker, 2015). Overall, enrollment of graduate degrees in nursing has increased in Canada (Canadian Nurses Association \& Canadian Association of Schools of Nursing, 2012). As these enrollments increase, the academic community must consider the realities of the graduate school experience, how students are socialized into faculties, and, most importantly, how integration and community in these programs are fostered because these experiences impact the graduate school experience and completion outcomes.

Despite the increases in graduate school enrollment, there is concern about graduate degree completion rates in this group. It is particularly difficult to specify the scope of the issue in the Canadian nursing context due to inconsistent reporting rates and metrics from universities; this has been identified as an issue since at least 2004 (Canadian Association for Graduate Studies, 2004). For example, an extensive study was conducted by the Council of Graduate Schools (2013) to analyse the rates and reasons for attrition at both the master's and doctoral levels, but only one eastern Canadian university was included in the analysis. Additionally, while completion rates are maintained by institutions, non-completion rates are infrequently maintained (Brill, Balcanoff, Land, Gogarty, \& Turner, 2014). However, in a sample of 15 Canadian universities in 2001, on average, only $70 \%$ of doctoral students finished their programs (Tamburri, 2013). Despite this gap in the literature, it has been identified that both graduation 
rates and completion times for graduate education in general in Canada are problematic (Canadian Association for Graduate Studies, 2004).

These (perceived) completion rates among graduate students are concerning (Goodare, 2015; Tamburri, 2013). Retention issues are often blamed on individual student characteristics such as lack of commitment; however, it has also been suggested that there are far more complex reasons beyond those of the individual for these attrition rates (Golde, 1998; Golde, 2000; Nesheim, Guentzel, Gansemer-Topf, Ross, \& Turrentine, 2006). In general, graduate students are poorly informed about the expectations of them or about the academic environment prior to starting their educational endeavours (Lovitts \& Nelson, 2000). Thus, program non-completion can be partially attributed to the graduate student being unaware of the relentless, intense commitment that is required of the student prior to program commencement; therefore, many graduate students leave their studies to pursue a more balanced life (Golde, 1998; Golde, 2000).

Researchers have demonstrated that graduate students who are in close contact with other graduate students have strong peer relationships and more successful integration and personal connections with the department or faculty. (Gansemer-Topf, Ross, \& Johnson, 2006; Golde, 1998; Golde, 2000; Nesheim et al., 2006; Rose, 2005; Tamburri, 2013). This has been attributed to the crucial role that informal knowledge sharing has during the graduate student transition period (Lovitts \& Nelson, 2000). Additionally, support during transition phases (i.e., coursework to research to thesis) is paramount to student success (Nesheim et al., 2006).

\section{Graduate School Experiences in Nursing}

Specific to the discipline of nursing, considerable research has been dedicated to studying stress levels and the effects of stress on student success in nursing programs (Hamrin, Weycer, Pachler, \& Fournier, 2006; Reilly \& Fitzpatrick, 2009; Timmins, Corroon, Byrne, \& Mooney, 2011). Researchers have demonstrated an inverse relationship between stress levels and a sense of belonging in doctoral nursing students; as stress levels among doctoral students decreases their sense of belonging increases (Reilly \& Fitzpatrick, 2009). Unfortunately, high levels of stress, a lack of collegial support, and feelings of not belonging are commonly identified graduate nursing school experiences (Goodare, 2015; Hamrin et al., 2006; Timmins et al., 2011). For graduate nursing education, these experiences are problematic because they prevent learners from meaningfully connecting to their education and learning environment (Jones, 2007).

There is still work to be done to foster and provide support to nurses pursuing advanced degrees (Jones, 2007; Nesheim et al., 2006; Reilly \& Fitzpatrick, 2009; Timmins et al., 2011). Mentorship programs can help students in developing a positive professional identity (Goodare, 2015). We argue that including relational learning opportunities in graduate education will contribute to the future success of the discipline of nursing while helping to decrease stress levels and promote leadership (Zhang, Qian, Wu, Wen \& Zhang, 2016).

\section{Mentoring in Graduate Nursing Education}

The definition of mentorship is varied depending on the context and the perspective of the participants and the intended outcome of the relationship (see American Psychological Association [APA], 2006; Wong et al., 2016; Zhang et al., 2016). For our purposes, we prefer a more traditional concept of mentorship, such as "a dyadic relationship between mentor and protégé, where the mentor draws on acquired knowledge and experience to enhance the professional and personal development of the less experienced protégé” (Tong \& Kram, 2013, p. 
218). Specific to Mentor Us, our understanding of mentorship can be found in our mission statement where we state that mentorship is intended to "enhance the quality of the Nursing Graduate student experience through the use of a peer-to-peer mentorship program that facilitates students' personal growth, confidence levels, leadership abilities, and academic success, to develop exceptional nursing scholars, practitioners, and leaders for the future" (About Us, n.d.).

Graduate student success is associated with positive interactions among existing students (Golde, 1998). Students must be encouraged to call on the existing support structures available to them in their learning environments (Timmins et al., 2011). One way to foster these connections is to encourage collegial support through the mentoring of graduate students by other graduate students. Mentorship programs foster relationships among members, help to strengthen a sense of personal and professional safety, provide academic and professional support, and promote collegial interactions (Garvey \& Westlander, 2013). These are necessary features to produce not only successful graduate students but also successful nurses with advanced degrees (Wong, Stake-Doucet, Lombardo, Sanzone, \& Tsimicalis, 2016). Reinforcing a sense of belonging among nurses in a graduate program is paramount to developing a professional identity; conversely, if nurses are not provided with positive socialization experiences, it can lead to dissatisfaction with their career (Goodare, 2015). Further, as nurses with advanced degrees move into faculty positions, they must be mentored into these roles to support scholarship and leadership positions within the faculty, community, and the discipline of nursing (Duncan, Mahara, \& Holmes, 2014). It has been suggested that the success of nursing scholarship is related to how well we mentor new nurses into leadership and research positions (Duncan et al., 2014; Goodare, 2015; Symonds-Brown \& Milner, 2015).

Mentoring programs in a variety of nursing environments have shown many benefits. Mentorship is beneficial to both the mentor and mentee, as it helps to increase self-confidence and self-esteem and contributes to defining successful career trajectories (APA, 2006; Garvey \& Westlander, 2013; Snowden \& Hardy, 2012; Tong \& Kram, 2013). Mentorship for new nurses who are moving into clinical practice helps to decrease turnover rates and contributes to increases in personal satisfaction, thus decreasing organizational costs to institutions (Zhang et al., 2016). Furthermore, mentoring in professional health care education has been shown to positively influence career development (Donovan \& Donovan, 2009). Also, there is evidence to support the understanding that as stress in graduate school decreases, satisfaction with professional programs increases. It is likely that mentorship programs in graduate nursing education would be beneficial (Zhang et al., 2016).

\section{Discussion}

Drawing on our knowledge from the literature related to mentorship and nursing graduate studies, we will now share our experiences with Mentor Us, including its structure, lessons learned, and plans regarding how the program will continue to evolve. The idea of developing a formal mentorship program for nursing graduate students was conceptualized by a group of master's students while participating in a transformative practice course. The spark of this idea led to a formalization of the program after much groundwork by the students. The vision, mission, and design (Appendix) for the Mentor Us program were readily supported by faculty members, and one-year funding was secured through a private faculty donor. In 2014, the Mentor Us website was launched as a place to house resources for interested participants.

Resources include program structure and expectations, role descriptions, goal development resources, links to support services on campus, academic funding opportunities, and job 
opportunities. By the summer of 2014, the founders were ready to begin their recruitment of the first cohort of mentors and mentees for the following academic year.

To ensure program sustainability, Mentor Us looked to the already established Nursing Graduate Student Association (NGSA) for support. The NGSA acts as the official voice for nursing graduate students at the university. As a part of its mandate, the NGSA hosts an annual Welcome Event for new graduate students. In the fall of 2014, this event was transformed into a collaborative event, whereby the NGSA and Mentor Us hosted its first Welcome and Matching Event. The Mentor Us founders, as well as graduate students who had signed up to be mentors over the summer, attended the event with the intention of meeting new students and networking with the community. This face-to-face interaction helped to foster familiarity with members, assess anticipated mentoring needs, and facilitate the appropriate matching of pairs.

In many cases, those responsible for the implementation and management of mentorship programs within schools of nursing are faculty members (Wong et al., 2016). At first glance, this structure is sensible, because students' time in graduate school is transitional and faculty often stay for years in their appointments. The Mentor Us program is unique when compared to other mentorship programs, as it was both conceptualized and exclusively administered by graduate nursing students.

\section{Structuring and Maintaining the Mentoring Relationship}

The appropriate pairing of mentors and mentees is fundamental for the success of a formal mentorship program (APA, 2006; Wong et al., 2016; Zhang et al., 2016). The founders of Mentor Us understood that for the program to be successful and sustainable, recruitment and matching of pairs were the crux of program success and built this into the development plan. To facilitate the pairing, a welcome package consisting of the program overview, a link to the website and registration form is emailed to incoming and continuing master's and doctoral nursing students. When students sign-up for the program, they are asked to provide some personal background information, such as specific program details, workplace experience, area of research interest and any preferences of who they would like to be matched with. This information is used to help determine the suitability of matches.

To create the best possible matches, two methods are used to assist in the process. Offering mentors and mentees the opportunity to select their own matches fosters a more compatible relationship and results in more satisfaction with the pairing (Allen, Eby, \& Lentz, 2006). Therefore, the first method is to encourage pairs to connect at the fall Welcome and Matching Event. Successful pairing is facilitated by the Mentor Us leadership team by encouraging networking and informal discussions among potential matches. Biographies of mentors are posted and available to potential mentees to assist with initial discussions. The second method for matching pairs is based on the application form demographics, student background, and the executive members' personal knowledge of their peers. The pairing decisions are made by the Mentor Us executive members based on these components (Wong et al., 2016). Members are then officially introduced through email and their data tracked via spread sheets.

Building a successful mentoring relationship is based on trust and openness (Yob \& Crawford, 2012). To reinforce candor and trustworthiness, the mentor and mentee are required to agree to the pairing and sign a one-year commitment and confidentiality form. These agreements align with the main tenets of the mentorship program, mainly, that the mentor-mentee 
relationship is based on mutual respect and that it exists within a safe space, where shared personal information is kept private. The commitment form emphasizes the formal nature of the relationship while the confidentiality portion helps to reinforce the trusting nature of the relationship.

Regular meetings and communication between mentorship pairs are important to the success of both the individual relationships and to the overall success of a mentoring program (Ramani, Gruppen, \& Kachur, 2006; Yob \& Crawford, 2012; Zhang et al., 2016). Over the course of the academic year, pairs are expected to meet at least once per semester and communicate on an as-needed basis. The method of communication is decided upon by the pairs such as text messaging, telephone calls, Skype, or in-person meetings to maintain connections.

One of the roles of a mentor is to introduce and help integrate the mentee into their shared community (Yob \& Crawford, 2012). As such, the Mentor Us team facilitates off-campus social events each semester called "Mentorship Cafes" to foster this engagement and positive integration into the community. As a means to increase student engagement and widen the program's reach, invitations to Mentorship Cafes were inclusive of all nursing graduate students, and not just those officially enrolled in the Mentor Us program. The cafes are intended to support larger community participation where mentors and mentees are invited to meet to discuss academic or non-academic related topics, such as:

- How do you get involved in groups and activities on campus?

- How do you manage your stress?

- What are your time management tips and tricks?

- How do you become a successful student?

These events are hosted at a coffee shop located close to the university and easily accessible by transit. Beverages are subsidized with Mentor Us program funding. To promote discussions among members who may not know each other, conversation starters are supplied. Mentorship Cafes are usually scheduled for two-hour blocks and tend to naturally conclude within that time frame. Informal feedback shared after the events are positive: attendees appreciate the opportunity to leave the confines of the university, meet face-to-face with their community of peers, and share graduate school experiences with each other.

\section{Mentor Training}

Mentors with formal training provide positive outcomes for mentees, thus it is often recognized as being a required component of successful mentorship programs (Garvey \& Westlander, 2013; Ramani et al., 2006; Zhang et al., 2016). A non-mandatory two-hour training session was developed and is presented at the beginning of the academic year. The training session is based on principles of adult learning (Garvey \& Westlander, 2013), and it covers diverse topics such as appropriate boundaries of mentorship relationships (APA, 2006), the important differences between the role of an academic advisor (a faculty role) and that of a mentor (a student role), and methods of effective communication. It is clearly communicated that there are expected safety limitations to the confidential nature of mentorship relationships, in that the mentor is required to report any conduct that goes against the university's Code of Student Behaviour, including the real or potential harm to one's self and or others. Mentor training also reviews available campus resources and services and provides opportunities to observe and role model effective communication styles via a role-playing activity. 
Presently, Gestalt psychology and the associated communication principles are used to frame mentor training. They are based on the worldview of existential phenomenology, an exploration of human existence and consciousness (Yontef \& Schulz, 2013). This approach assumes that human beings are inherently "good", and continually strive towards wholeness, which is only realized when that person's unique, maximum human potential is achieved (Bednářová, 2009; Pettit, 1976). It also recognizes that every individual has their own unique perspectives, preferences, experiences, and strengths. From a mentorship perspective, utilization of Gestalt principles allows for the mentoring relationship to be founded on mutual respect and individual ownership of decision-making (Bednářová, 2009). Therefore, instead of onedirectional advice giving, the connection between mentor and mentee is based on "an opportunity for mutuality and collaborations" (Spoth, Toman, Leichtman, \& Allan, 2013, p. 386). The focus of interactions is on sharing personal, lived experiences rather than analyzing singular parts (Clegg, 2010). This theoretical framing is important to the program because it provides a common foundation and intervention guideline for all members.

The idea to utilize Gestalt communication principles as a foundational piece of the training program was derived from the Faculty of Science mentorship program at the university. In particular, the training draws attention to the inherent power imbalance of the relationship; this dynamic reinforces the power differential between an "experienced" mentor and a "novice" mentee, and it can increase the potential for conflict, ill feelings, blame, and shame. In contrast, Gestalt psychology when applied to mentorship allows for a more egalitarian approach to the relationship by focusing on the exchange of real-life experience between mentors and mentees. Using Gestalt principles can be as simple as framing communication via experiential sharing, allowing for meaningful exchanges fostered by strategic language choices (L. Hayes \& S. Hesse, personal communication, June 25, 2016).

While the roots of Gestalt psychology are therapeutic in nature, the mandate of the Mentor Us program is to provide a supportive environment and open communication between members, rather than attempt amateur psychology. In training, mentors are offered the opportunity to watch and participate in role playing behaviour, demonstrate traditional advice giving, and then contrast this with Gestalt communication and peer coaching through experience sharing.

\section{Lessons Learned and Moving Forward}

Now into its third year, the program is designed and run much the same way as it was in its first year: a leadership team recruits mentors and mentees over the summer, Mentor Us and the NGSA collaborate for the Welcome and Matching Event, mentor training is offered, and community-building events are facilitated. Faculty and student interest in the program continues to grow; student participation in Mentor Us increased by $23 \%$ from its first to second year with 51 students registered. This growth suggests the value and efficacy of the program for nursing graduate students and is anecdotally reinforced as participants have indicated through evaluations that Mentor Us has helped them feel supported and connected to the academic and wider university community.

Though the program has seen success in achieving many of its aims and goals, the leadership team has learned a variety of lessons that would be valuable to others intent on developing a mentorship program. First, specific student populations require attention; in our case, students in the online doctoral program and international students who study locally at the 
university. Literature suggests that it is critical to enculturate international students into the community (Rose, 2005). When a student from the online doctoral cohort approached Mentor Us about securing a mentor last year, a second wave of recruitment for mentors and mentee was initiated with success: all the online doctoral students were matched with mentors. Recruitment and engagement initiatives with this population subset have been received positively. Comparatively, strategies to engage international students within Mentor Us have not been met with the same success. Efforts such as an assigned executive to facilitate connection with international students did not result in increased engagement as expected. The Mentor Us executive has connected with the faculty's International Nursing Advisory Committee and continues to explore new ways to meet the mentorship needs of international students.

Second, mentor training initiatives require improvement in two specific ways. Primarily, the theoretical principles the training is based on need to be reconsidered. In conducting a literature review for this paper, we discovered that the Gestalt communication strategy (called Gestalt Language Protocol) used in the current Mentor Us training, were originally created by a group of expert entrepreneurs who used them in the business realm (L. Hayes, personal communication, June 25, 2016). Anecdotally, it seems the communication principles are effective; however there is essentially no research evidence to substantiate this claim. This is not to say that the principles are not useful, but we suggest that they require further research to evaluate their effectiveness. In consideration of this, we are currently seeking alternate methods of fostering communication for our mentor training. Secondarily, concern with the low turnout for mentor training is an issue to be addressed. The leadership team is working on ways to increase training engagement by considering factors such as scheduling, time commitment, content, and alternative delivery methods. For mentoring programs to flourish, the continuous evaluation and reassessment of program needs are necessary (Ramani et al., 2006). There are plans to undertake more formal evaluations of the training in the coming year.

Third, though most were, not all the mentorship matches were successful. The year-end evaluations highlighted some common problems such as scheduling conflicts, inadequate commitment from either person, or the mentor's lack of specific content knowledge of interest to the mentee. As discussed, the pairing of mentors with mentees is important to the success of the relationships (Rose, 2005; Zhang et al., 2016). One way to facilitate improved matching is to collect more demographics of the mentors and mentees at the outset. Pairing the dyads in part based on demographics has been shown to contribute to successful matches (APA, 2006; Wong et al., 2016). We have altered our recruitment package to better reflect needs we anticipate will result in more successful matching. Another idea for future consideration is to move towards a model of mentorship that fosters multiple relationships within a larger social group, sometimes called "developmental networks" (Tong \& Kram, 2013, p. 231). These developmental networks allow a mentee to have several mentors, each with specific functions.

Fourth, the most complicated design feature of the Mentor Us program is that its leadership structure is completely dependent on the efforts of its student executive, which transitions every year as graduate students move through their respective programs. The sustainability of the program is entirely dependent on the succession plan installed by the leadership team of the preceding year. In its inaugural year, the four founders made the decision to elect four other executives to their leadership team to launch effectively the program. Program planning and evaluation duties were allocated amongst members. However, no long-term or multi-year commitment was required by this team of executives, and program sustainability was 
questionable at the end of the first year. To mitigate this uncertainty in the future, in the second year of the program, the two co-directors made the decision to select two supporting leadership team executives agreeing to a two-year commitment, who would be mentored into the codirector roles for the subsequent academic year. This transitional model of leadership provides a unique solution to the fluid nature of graduate studies and reflects the program's existing mission statement, vision, and program aims (Appendix). This particular leadership framework allows the year's Directors to respond to program needs in a timely and flexible fashion.

Finally, as the program continues to develop, it is important to measure effectiveness and fidelity and track long-term outcomes in order to determine trends in student attrition from nursing graduate school before and after the implementation of the Mentor Us program. A survey has been developed in consultation with faculty expertise, personal experiences, and program evaluation resources (Chen, 2015) that will measure program effectiveness quantitatively. Over the next year, interviews and focus groups will take place to better understand the effects of the program on participants. Additionally, we will review recently published research that has formally evaluated mentorship programs for early career nursing faculty (Brody et al., 2016) and a mentorship program for Turkish nurses (Vatan \& Temel, 2016). This research may contribute to a reframing or rewriting of our currently used evaluations.

\section{Conclusion}

Overall, the Mentor Us program is designed to offer social support to mentees by means of sharing coping strategies, study tips, and engaging in goal setting. It is thought that the mentorship offered will help with the acclimatization of the mentee to nursing graduate school. However, the mentor does not leave the mentorship relationship without having acquired benefits as well. The mentor gains leadership experience and a proficiency in exhibiting effective communication strategies.

The Mentor Us leadership team believes that its efforts have helped to unite students and enhance their accessibility to the community, increasing commitment and cohesion among students in the nursing faculty. The program promotes leadership skill development, collegiality, and improved student outcomes. We recommend mentorship as a productive means of retaining nursing graduate students at universities and improving the graduate student experience. Mentorship in nursing is crucial to the development of exceptional nursing leaders and will be even more important as nurses continue to undertake leadership roles.

Finally, as part of the process of writing this paper, we have discovered that there is a significant paucity of data surrounding completion rates and reasons for non-completion in graduate studies, especially in nursing. From our perspective, this is an area ripe for research, as graduate degree-prepared nurses are essential to the further development of the discipline of nursing. 


\section{References}

About us. (n.d.). Retrieved from http://www.mentor-us.com/about-us/

Allen, T. D., Eby, L. T., \& Lentz, E. (2006). Mentorship behaviors and mentorship quality associated with formal mentoring programs: Closing the gap between research and practice. Journal of Applied Psychology, 91(3), 567-578. https://doi.org/10.1037/00219010.91.3.567

American Psychological Association (APA). (2006). Introduction to mentoring: A guide for mentors and mentees. Retrieved from https://www.apa.org/education/grad/mentoringcare.aspx

Bednářová, D. (2009). Applying Gestalt therapy principles in counseling a female orienteer. Acta Universitatis Palackianae Olomucensis. Gymnica, 39(1), 17-25.

Brill, J. L., Balcanoff, K. K., Land, D., Gogarty, M., \& Turner, F. (2014). Best practices in doctoral retention: Mentoring. Higher Learning Research Communications, 4(2), 26-37. https://doi.org/10.18870/hlrc.v4i2.186

Brody, A. A., Edelman, L., Siegel, E. O., Foster, V., Jr.Bailey, D. E., Bryant, A. L., \& Bond, S. M. (2016). Evaluation of a peer mentoring program for early career gerontological nursing faculty and its potential for application to other fields in nursing and health sciences. Nursing Outlook, 64(4), 332. https://doi.org/10.1016/j.outlook.2016.03.004

Canadian Association for Graduate Studies. (2004). The completion of graduate studies in Canadian universities: Report and recommendations October 2003. Retrieved from http://www.cags.ca/documents/publications/working/completion_grad_studies_2004.pdf

Canadian Nurses Association. (2008). Advanced nursing practice: A national framework 2008. Retrieved from https://www.cna-aiic.ca/ /media/cna/page-content/pdfen/anp_national_framework_e.pdf

Canadian Nurses Association \& Canadian Association of Schools of Nursing. (2012). Registered nurses education in Canada statistics 2009-2010: Registered nurse workforce: Canadian production: Potential new supply. Retrieved from https://cnaaiic.ca/ /media/cna/files/en/nsfs_report_2011-2012_e.pdf

Chen, H. (2015). Practical program evaluation: Theory-driven evaluation and the integrated evaluation perspective (2nd ed.). Los Angelas, CA: Sage.

Clegg, K. (2010). Some Gestalt contributions to psychiatry. Journal of Psychiatric Practice,16(4), 250-252. doi:10.1097/01.pra.0000386911.39440.11

Cotterill-Walker, S. M. (2012). Where is the evidence that master's level nursing education makes a difference to patient care? A literature review. Nurse Education Today, 32(1), 5764. doi:10.1016/j.nedt.2011.02.001

Council of Graduate Schools. (2013). Completion and Attrition in STEM Master's Programs: Pilot Study Findings. Retreived from http://cgsnet.org/completion-and-attrition-stemmasters-programs-pilot-study-findings 
Donovan, A., \& Donovan, J. (2009). Mentorship in postgraduate training programmes: Views of Canadian programme directors. Medical Education, 43, 155-158. doi:10.1111/j.13652923.2008.03258.x

Drennan, J. (2010). Critical thinking as an outcome of a Master's degree in nursing programme. Journal of Advanced Nursing, 66(2), 422-431. doi:10.1111/j.1365-2648.2009.05170.x

Drennan, J. (2012). Masters in nursing degrees: An evaluation of management and leadership outcomes using a retrospective pre-test design. Journal of Nursing Management, 20(1), 102-112. doi:10.1111/j.1365-2834.2011.01346.x

Duncan, S. M., Mahara, S., \& Holmes, V. (2014). Confronting the social mandate for nursing scholarship - One school of nursing's journey. Quality Advancement in Nursing Education - Advances en formation infirmiere, 1(1). https://doi.org/10.17483/2368-6669.1018

Edge, J., \& Munro, D. (2015). Inside and outside the academy: Valuing and preparing PhDs for careers. Retrieved from http://www.conferenceboard.ca/e-library/abstract.aspx?did=7564

Gansemer-Topf, A. M., Ross, L. E., \& Johnson, R. M. (2006). Graduate and professional student development and student affairs. New Directions for Student Services, 115, 19-30. doi:10.1002/ss.213

Garvey, R., \& Westlander, G. (2013). Training mentors - Behaviors which bring positive outcomes in mentoring. In J. Passmore, D. B. Peterson, \& T. Freire (Eds.) The WileyBlackwell handbook of the psychology of coaching and mentoring (pp. 243-265). Chichester, West Sussex: Wiley-Blackwell.

Golde, C. M. (1998). Beginning graduate school: Explaining first-year doctoral attrition. New Directions for Higher Education, 101, 55-64. https://doi.org/10.1002/he.10105

Golde, C. M. (2000). Should I stay or should I go? Student descriptions of the doctoral attrition process. The Review of Higher Education, 23(2), 199-227. https://doi.org/10.1353/rhe.2000.0004

Goodare, P. (2015). Literature review: 'Are you ok there?' The socialisation of student and graduate nurses: Do we have it right? Australian Journal of Advanced Nursing, 1, 38-43.

Hamrin, V., Weycer, A., Pachler, M., \& Fournier, D. (2006). Evaluation of peer-led support groups for graduate nursing students. Journal of Nursing Education, 45(1), 39-43.

Jones, A. (2007). Still crazy after all these years. Nurse Education Today, 27(5), 365-366. doi:10.1016/j.nedt.2007.04.006

Looker, D. (2015). 41st statistical report Canadian Association for Graduate Studies 2015. Retrieved from http://www.cags.ca/statistical_reports.php

Lovitts, B. E., \& Nelson, C. (2000). The hidden crisis in graduate education: Attrition from Ph.D. programs. Academe, 6, 44-50. https://doi.org/10.2307/40251951

Nesheim, B. E., Guentzel, M. J., Gansemer-Topf, A. M., Ross, L. E., \& Turrentine, C. G. (2006). If you want to know, ask: Assessing the needs and experiences of graduate students. New Directions for Student Services, 115, 5-17. https://doi.org/10.1002/ss.212 
Pettit, J. D. (1976). On the interrelationship of transactional analysis and Gestalt psychology with applications to communication theory and practice. Journal of Business Communication, 14(1), 41-45. https://doi.org/10.1177/002194367601400106

Pilon, B., Crutcher, T. D., Leming-Lee, S., Watters, R., Wolgast, K. A., \& Arnow, D. (2014). The value proposition for graduate education of emerging nurse leaders: immediate benefit to organizations. Nurse Leader, 12, 81-85. doi:10.1016/j.mnl.2013.11.004

Ramani, S., Gruppen, L., \& Kachur, E., K. (2006). Twelve tips for developing effective mentors. Medical Teacher, 28(5), 404-408. doi:10.1080/01421590600825326

Reilly, J. R., \& Fitzpatrick, J. J. (2009). Perceived stress and sense of belonging in doctor of nursing practice students. Journal of Professional Nursing, 2, 81-86.

https://doi.org/10.1016/j.profnurs.2008.10.002

Rose, G. L. (2005). Group differences in graduate students' concepts of the ideal mentor. Research in Higher Education, 46(1), 53-80. https://doi.org/10.1007/s11162-004-6289-4

Scully, A. A. (2015). Mentorship and novice nursing faculty: Working together for successful role transitioning (Doctoral dissertation, University of Alberta, Edmonton, AB). Retrieved from https://era.library.ualberta.ca/files/f7623g09q/Sculley_Azizah_A_201501_PhD.pdf

Singh, M. D., Pilkington, F. B., \& Patrick, L. (2014). Empowerment and mentoring in nursing academia. International Journal of Nursing Education Scholarship, 11(1), 1. doi:10.1515/ijnes-2013-0070

Snowden, M., \& Hardy, T. (2012). Peer mentorship and positive effects on student mentor and mentee retention and academic success. Widening Participation \& Lifelong Learning, 14, 76-92. https://doi.org/10.5456/wpll.14.s.76

Spoth, J., Toman, S., Leichtman, R., \& Allan, J. (2013). Gestalt approach. In: J. Passmore, D. B. Peterson \& T. Freire (Eds.) The Wiley-Blackwell handbook of the psychology of coaching and mentoring (pp. 385-406). Chichester, West Sussex: Wiley-Blackwell.

Symonds-Brown, H. J., \& Milner, M. F. (2015). Breaking from tradition: Transforming leadership education in nursing. Quality Advancement in Nursing Education - Advancees en formation infirmiere, 1(3), 1-15. https://doi.org/10.17483/2368-6669.1041

Tamburri, R. (2013). The PhD is in need of revision. University Affairs, 3(54), 12-21. Retrieved from http://www.universityaffairs.ca/features/feature-article/the-phd-is-in-need-ofrevision/

Timmins, F., Corroon, A., Byrne, G., \& Mooney, B. (2011). The challenge of contemporary nurse education programmes. Perceived stressors of nursing students: Mental health and related lifestyle issues. Journal of Psychiatric and Mental Health Nursing, 9, 758-766. https://doi.org/10.1111/j.1365-2850.2011.01780.x

Tong, C., \& Kram, K. E. (2013). The efficacy of mentoring - the benefits for mentees, mentors, and organizations. In: J. Passmore, D. B. Peterson \& T. Freire (Eds.) The Wiley-Blackwell handbook of the psychology of coaching and mentoring (pp. 217-242). Chichester, West Sussex: Wiley-Blackwell.

Vatan, F., \& Temel, A. B. (2016). A leadership development program through mentorship for clinical nurses in Turkey. Nursing Economics, 34(5), 242-250. 
Warren, J. I., \& Mills, M. E. (2009). Motivating registered nurses to return for an advanced degree. Journal of Continuing Education in Nursing, 40(5), 200-207. https://doi.org/10.3928/00220124-20090422-01

Watkins, D. (2011). The influence of Masters education on the professional lives of British and German nurses and the further professionalization of nursing. Journal of Advanced Nursing, 67(12), 2605-2614. doi:10.1111/j.1365-2648.2011.05698.x

Wong, C., Stake-Doucet, N., Lombardo, C., Sanzone, L., \& Tsimicalis, A. (2016). An Integrative review of peer mentorship programs for undergraduate nursing students. Journal of Nursing Education, 55(3), 141-149. doi:10.3928/01484834-20160216-04

Yob, I. M., \& Crawford, L. (2012). Conceptual framework for mentoring doctoral students. Higher Learning Research Communications, 2(2), 34-47. https://doi.org/10.18870/hlrc.v2i2.66

Yontef, G. \& Schulz, F. (2013). Dialogic relationship and creative techniques: Are they on the same team? Pacific Gestalt Institute. Retrieved from http://www.gestalttherapy.org/wpcontent/uploads/2014/09/experiments.pdf

Zhang, Y., Qian, Y., Wu, J., Wen, F., \& Zhang, Y. (2016). The effectiveness and implementation of mentoring program for newly graduated nurses: A systematic review. Nurse Education Today, 37, 136-144. https://doi.org/10.1016/j.nedt.2015.11.027 


\section{Appendix}

Mission of Mentor Us: To enhance the quality of the Nursing Graduate student experience through the use of a peer-to-peer mentorship program that facilitates students' personal growth, confidence levels, leadership abilities, and academic success, to develop exceptional nursing scholars, practitioners, and leaders for the future.

Vision of Mentor Us: Mentor Us envisions an academic community in which nursing students of all backgrounds and programs experience empowering relationships and community networking.

Purpose of Mentor Us: The purpose of Mentor Us is to build community and promote a connection between undergraduate, masters and $\mathrm{PhD}$ students alike. Furthermore, it will address the needs of specific at-risk populations such as our international and distance students. Growth opportunities will be provided for both student mentors and mentees. Mentees will receive support, direction, and motivation from their mentors, while mentors will develop their personal, active listening, and leadership skills. 